\title{
Features of metallurgy waste mainly processing with account for raw material contrast
}

\author{
Alexander Burdonov ${ }^{1 *}$, Vyacheslav Barakhtenko ${ }^{1}$, Konstantin Prokhorov ${ }^{2}$ and Yuri \\ Novikov $^{1}$ \\ ${ }^{1}$ FSBEI HE Irkutsk National Research Technical University, 664074, Irkutsk, Russia \\ ${ }^{2}$ Mining Institute FEB RAS, 51 Turgenev st., Khabarovsk, 680000, Russia
}

\begin{abstract}
Annotation. This work presents research studies of alumina-containing estimates formed during the production of aluminum on electrolyzers with self-burning anodes during technological operations at PJSC RUSAL Bratsk. Material from the territory of the electrolysis workshop, with a mark of \pm 0 , is a mixture of finely dispersed powder, $2.5 \mathrm{~mm}$ in size (on average $62.78 \%$ by weight) with pieces of material from 0.5 to $6 \mathrm{~cm}$ in size. , $26 \%$ by weight). As a result of the work, the particle size and chemicalmetallurgical properties of an alumina-containing estimate were studied. During the research, the content of valuable components and impurities in the sample of various classes was determined. In the process of mineralogical analysis, two phases were identified in the products: dark, black-gray and light, grayish-white. It is proved that these phases have significant differences in the chemical composition of the feed. Spectroscopic studies showed significant differences in the colorimetric characteristics of the raw materials, which is a fundamental factor for the use of photometric separation. Based on preliminary studies on the separation of alumina-containing estimates by photometric separation, the fundamental possibility of purifying contaminated material from technological impurities has been established.
\end{abstract}

\section{Introduction}

The metallurgical industry makes a significant contribution to environmental pollution, in particular, the production of aluminum by electrolysis of cryolite-alumina melts [1-3]. However, industrial enterprises improve environmental production indicators [4], develop and implement low-waste production technologies [4-6].

Nevertheless, the issue of processing metallurgical waste is still relevant. Most waste contains valuable components, which increases the relevance of their recycling [1].

It should be noted that wide coverage of scientific and technological developments, their theoretical analysis, correlation with the experience of metallurgical enterprises will have an important role in the field of non-ferrous metallurgy.

An important aspect of increasing the efficiency of aluminum production is resource conservation and environmental management, which is caused by the development of integrated methods for the disposal of aluminum production waste.

\footnotetext{
${ }^{*}$ Corresponding author: slimbul@rambler.ru
} 
The main reason for the formation of a large amount of waste at Russian primary aluminum enterprises is the use of cryolite-alumina melt electrolysis technology with the installation of baths with a self-burning anode - with the Soderberg anode [7]. Abroad, aluminum is produced in electrolyzers with prebaked anodes. Enterprises are equipped with a "dry" system for purification of waste process gases. Along with higher technical and economic indicators, with such an organization, the process is characterized by greater environmental safety of production due to the absence of emissions of hydrocarbons contained in the binder of the self-burning anode. In addition, there is no waste of flotation processing of removable coal foam (flotation tailings) and solutions of "wet" gas purification (gas purification sludge). And also significantly reduces the amount of this type of waste generated (the type of use of automatic feed of raw materials and fluorine salts), as a mechanical mixture of alumina and recycled (secondary) electrolyte, called "estimates" or "estimates", which wakes up to "zero" marks of electrolysis cases when loading in baths and subsequently collected by dust collectors (PUM)) $[1,8]$.

Estimates are waste of complex variable composition, swept away in the electrolysis shops. An interest in their processing lies in the fact that they contain a significant amount of valuable components $\left(\mathrm{Na}_{3} \mathrm{AlF}_{6}, \mathrm{Al}_{2} \mathrm{O}_{3}, \mathrm{AlF}_{3}\right)$, the extraction of which and reuse in the production of aluminum can help reduce the cost of production. However, in addition to valuable components, the estimate includes iron and silicon-containing compounds $(\mathrm{SiO} 2$, $\mathrm{Fe} 2 \mathrm{O} 3$ ), which, when they enter the electrolyte, adversely affect the electrolysis process.

In the process of estimating, finely dispersed particles of valuable alumina are mixed with various materials (pieces of asphalt and concrete, sand, solidified metal splashes, etc.), which makes it impossible to return it to the technological process.

Alumina used in the electrolysis process and partially transferred to estimates is supplied to aluminum plants in Russia, in particular PJSC RUSAL Bratsk, not only from Russian producers, for example, from RUSAL Achinsk JSC (Achinsk Alumina Refinery), but also from Kazakhstan, Guinea, Australia and Italy, which leads to a significant increase in the cost of production of aluminum [9-10].

The research results presented in the article are part of a comprehensive work on topics dedicated to the study of the composition and properties of alumina-containing estimates, as well as the analysis and search for ways to prepare it for a possible return to aluminum production.

The purpose of the research was to study the process of processing alumina-containing estimates of PJSC RUSAL Bratsk (Bratsk Aluminum Plant) for a possible return to the electrolysis process.

\section{Formulation of the problem}

The object of research was the alumina-containing estimates of PJSC RUSAL Bratsk. For electrolyzers with self-baking anodes, due to the absence of stationary bins, the so-called inline or regulated bath processing method is used, during which the electrolyte crust is destroyed from one of the longitudinal sides of the electrolyzer and alumina is loaded with alumina distribution machines. During these flow-regulated processing of electrolyzers during the distribution of alumina, the raw material spills onto metal corrugated plates resting at one end on the cathode casing, and then to zero. Also, losses occur during refueling with alumina processing equipment.

Due to the interaction of electrolysis products and alumina spills with infrastructure and the environment (concrete base, metal structures, dust, soil), the feedstock is contaminated, which makes it impossible to use it in the production of primary aluminum. 
To select the optimal scheme for processing the estimate, it was necessary to study the phasechemical and particle size distribution, and other characteristics of the raw material. Detailed research results are presented in $[8,11]$.

\section{Research part}

Based on the complex of studies, the distribution of polluting components by size classes was established. It was found that the sample of alumina-containing estimates consists of cryolite $\left(\mathrm{Na}_{3} \mathrm{AlF}_{6}\right)$, chiolite $\left(\mathrm{Al}_{3} \mathrm{~F}_{14} \mathrm{Na}_{5}\right)$, corundum $\left(\mathrm{Al}_{2} \mathrm{O}_{3}\right)$. quartz $\left(\mathrm{SiO}_{2}\right)$, feldspar $(\mathrm{Ca}, \mathrm{Na})(\mathrm{Al}, \mathrm{Si})$ $\left.\mathrm{AlSi}_{2} \mathrm{O}_{8}\right)$ ), carbonaceous matter and anthropogenic phase composition $(\mathrm{NaF}) \cdot 1,5 \mathrm{CaF}_{2}$. $\mathrm{AlF}_{3}$. Material in different particle sizes differs only in phase ratio. Each fraction was studied with a binocular microscope. Two phases were detected in the samples: dark, black-gray and light, grayish-white. The light phase is represented mainly by spheres that differ only in size. Two mono fractions were isolated from the products. For each of their fractions, the chemical composition is determined (table 1). In the quantitative ratio in all products, the light gray phase predominates (the ratio of fractions in the samples is 90: 10-95: 5).

Table 1. Incomplete chemical composition of the main mono-fractions

\begin{tabular}{|c|c|c|}
\hline \multirow{2}{*}{ Ellement } & \multicolumn{2}{|c|}{ Mass percentage of ellement, \% } \\
\cline { 2 - 3 } & $\begin{array}{c}\text { Bright } \\
\text { (grayish white mass) }\end{array}$ & $\begin{array}{c}\text { Dark } \\
\text { (grayish black mass) }\end{array}$ \\
\hline $\mathrm{Al}_{2} \mathrm{O}_{3}$ & 27.8 & 15.7 \\
\hline $\mathrm{CaO}$ & 5.85 & 4.07 \\
\hline $\mathrm{Fe}_{2} \mathrm{O}_{3}$ & 0.179 & 3.62 \\
\hline $\mathrm{SiO}_{2}$ & 1.06 & 31.0 \\
\hline
\end{tabular}

The data obtained allow us to conclude that the exclusion of the dark (grayish-black mass) will significantly solve the research task. Based on the hypothesis put forward, the colorimetric characteristics of alumina-containing raw materials were studied as the main sign of differences in the components of the mixture.

From the initial estimate sample, 10 samples with a particle size of $-30+10 \mathrm{~mm}$ were isolated. Diffuse reflectance spectra of alumina-containing estimate samples (average sample, fraction $-30+10 \mathrm{~mm}$ ) were measured on an MSFU-312 microspectrophotometer in accordance with Methodological Recommendations No. 17 "Diffuse Reflectance Spectra" (SIMS, 1988). As a reference, a certified sample of milk glass MS-20 was used. The calculation of the optical characteristics $(\mathrm{x}, \mathrm{y}, \mathrm{R} ; \mathrm{L} *, \mathrm{a} *, \mathrm{~b} *)$ is made according to the formulas in accordance with GOST R ISO 105-J01-99 "Requirements for the instrumental method of measuring surface color." Calculations are made for a standard light source C.

Photographic documentation of the samples was performed using a Canon EOS 600D digital apparatus under fluorescent lighting. Color correction was made on the model of milk glass MS-20.

To study the possibility of using alumina-containing estimates as the dividing characteristic in photometric separation, 7 groups of samples were identified. Some of the samples are shown in Figure 1-4.

The diffuse reflection spectrum of one of the samples of an alumina-containing estimate is shown in Fig. 5. The colorimetric characteristics of the samples are shown in table 2. 


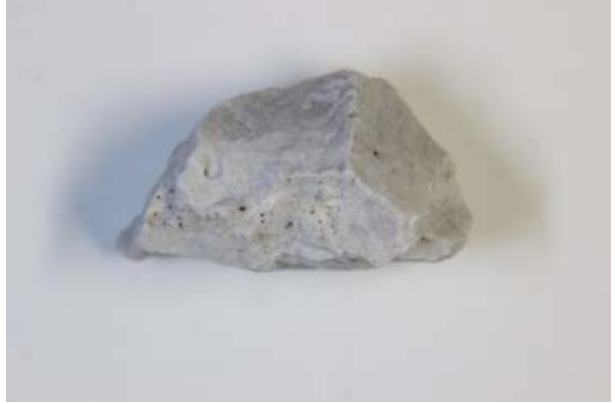

a)

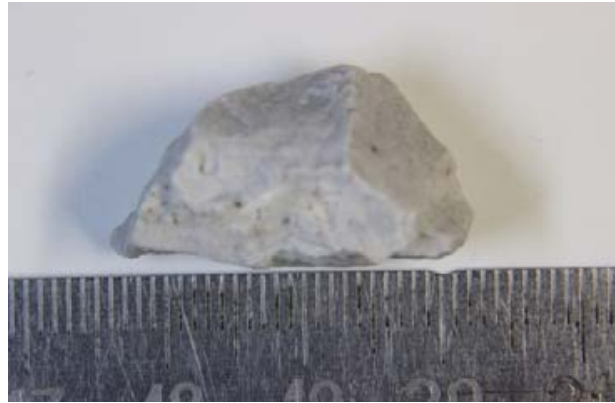

б)

Fig. 1. Group 1. Image: a) - Sample of alumina-containing estimate No. 1.1; b) - The same sample with a ruler
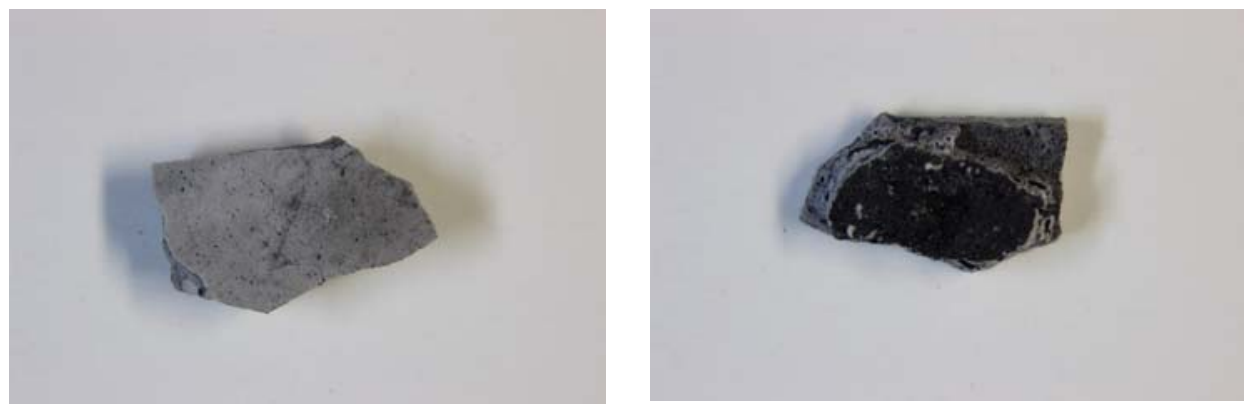

Fig. 2. Sample of alumina-containing estimate No. 3.2
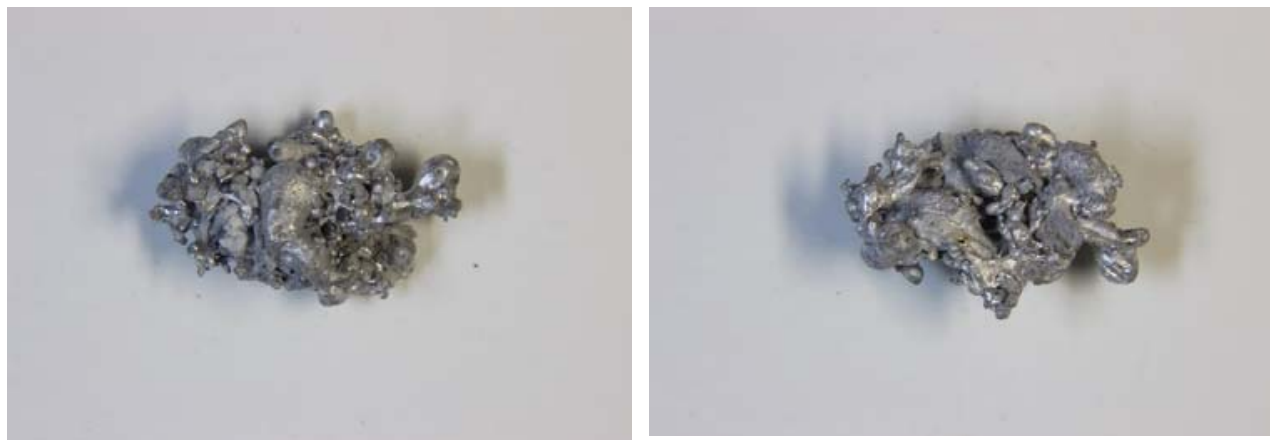

Fig. 3. Sample of alumina-containing estimate No. 5.1
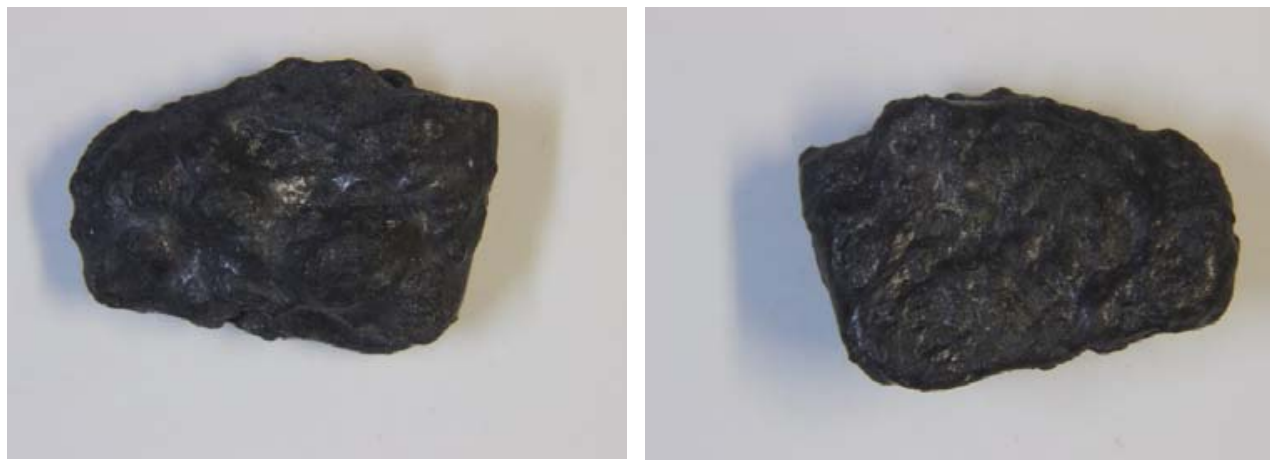

Fig. 4. sample of alumina-containing estimate No. 7. 
* Figures 1-4 show samples of an alumina-containing estimate with significant differences in colorimetric properties.

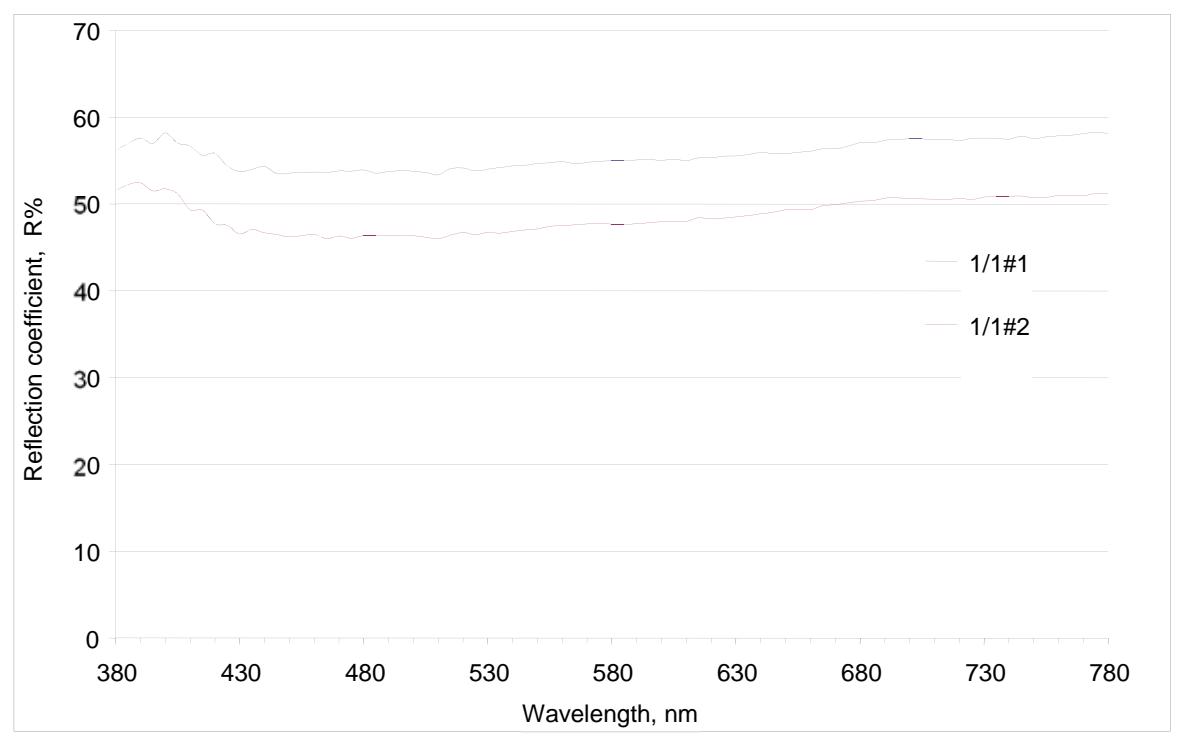

Fig. 5. Spectra of diffuse reflection of the sample alumina estimate No. 1.1

Table 2. Colorimetric characteristics of the samples

\begin{tabular}{|c|c|c|c|c|c|c|}
\hline $\begin{array}{c}\text { Points measuring } \\
\text { on a sample }\end{array}$ & $\mathrm{x}$ & $\mathrm{y}$ & $\mathrm{L} *$ & $\mathrm{a}^{*}$ & $\mathrm{~b}^{*}$ & $\mathrm{R}^{* *}$ \\
\hline $1 / 1 \# 1$ & 0,313 & 0,317 & 78,846 & 0,678 & 0,697 & 54,606 \\
\hline $1 / 1 \# 2$ & 0,314 & 0,317 & 74,419 & 1,082 & 0,777 & 47,310 \\
\hline $1 / 2 \# 1$ & 0,311 & 0,316 & 82,149 & 0,715 & 0,156 & 60,512 \\
\hline $1 / 2 \# 2$ & 0,312 & 0,317 & 87,569 & 0,590 & 0,406 & 71,101 \\
\hline $2 / 1 \# 1$ & 0,317 & 0,319 & 90,388 & 2,021 & 2,135 & 77,066 \\
\hline $2 / 1 \# 2$ & 0,313 & 0,317 & 91,555 & 0,576 & 0,884 & 79,628 \\
\hline $2 / 2 \# 1$ & 0,313 & 0,313 & 69,814 & 2,367 & $-0,457$ & 40,444 \\
\hline $2 / 2 \# 2$ & 0,316 & 0,319 & 76,581 & 1,125 & 1,721 & 50,786 \\
\hline $3 / 1 \# 1$ & 0,301 & 0,301 & 55,870 & 2,154 & $-4,832$ & 23,759 \\
\hline $3 / 1 \# 2$ & 0,290 & 0,289 & 46,529 & 2,260 & $-7,814$ & 15,647 \\
\hline $3 / 1 \# 3$ & 0,310 & 0,307 & 54,040 & 2,873 & $-2,293$ & 21,990 \\
\hline $3 / 2 \# 1$ & 0,304 & 0,306 & 67,344 & 1,201 & $-3,571$ & 37,051 \\
\hline $3 / 2 \# 2$ & 0,287 & 0,277 & 37,792 & 4,331 & $-9,374$ & 9,961 \\
\hline $3 / 2 \# 3$ & 0,303 & 0,305 & 61,739 & 1,396 & $-3,800$ & 30,067 \\
\hline $4 / 1 \# 1$ & 0,312 & 0,320 & 76,761 & $-1,039$ & 1,539 & 51,083 \\
\hline $4 / 1 \# 2$ & 0,327 & 0,300 & 47,054 & 9,775 & $-1,735$ & 16,044 \\
\hline $5 / 1 \# 1$ & 0,310 & 0,315 & 95,279 & 0,420 & $-0,475$ & 88,189 \\
\hline $5 / 1 \# 2$ & 0,302 & 0,317 & 85,934 & $-3,973$ & $-1,082$ & 67,786 \\
\hline $6 / 1 \# 1$ & 0,282 & 0,264 & 33,491 & 6,297 & $-11,427$ & 7,758 \\
\hline $6 / 1 \# 2$ & 0,302 & 0,292 & 42,203 & 4,647 & $-5,666$ & 12,619 \\
\hline $7 / 1 \# 1$ & 0,295 & 0,289 & 43,790 & 3,644 & $-6,987$ & 13,679 \\
\hline $7 / 1 \# 2$ & 0,256 & 0,227 & 22,965 & 7,990 & $-16,395$ & 3,786 \\
\hline
\end{tabular}

** - Reflection coefficient (R) 
The obtained results of spectroscopic studies of samples of alumina-containing estimates showed significant differences in reflection coefficient $(\mathrm{R}=3,786-88,189)$ in the entire visible region of light, which is a favorable factor for the application of the photometric separation method.

Based on the hypothesis put forward, studies were conducted on the separation of monofractions with different contents of valuable components using the method of photometric separation.

As a result of the photometric separation of the aluminum production waste sample from the size class of $-20+5 \mathrm{~mm}$, it was possible to isolate an alumina-containing product $(\Sigma$ alumina product 1.2 ) with an $\mathrm{Al}$ content of $30.14 \%, \mathrm{Si}-0.41 \%, \mathrm{Fe}-0.1 \%$, when extracting aluminum from the entire mass of the sample $2.76 \%$. It should be noted that in the process of photometric separation, it was possible to reduce the Si content in the product by 4 times compared with its content in the initial fineness class, the Fe content decreased by 4.7 times.

As a final part of a research on a separation of the particle size class $-50+20 \mathrm{~mm}$, an alumina-containing product ( $\Sigma$ alumina product 5.6 ) with an $\mathrm{Al}$ content of $22.24 \%$, Si $0.41 \%, \mathrm{Fe}-0.12 \%$ was isolated when aluminum was extracted from it the entire mass of the sample is $4.58 \%$. It was possible to reduce the $\mathrm{Si}$ content in the product in comparison with its content in the initial size class by 2.6 times, the Fe content decreased by 2.1 times.

The main losses of aluminum $(84.9 \%)$ are associated with the elimination of photometric separation due to its high yield $-74.19 \%$. Loss of aluminum with tailings of photometric separation ( $\Sigma$ alumina-containing product $3,4,7,8)$ is $7.76 \%$.

\section{Findings}

Eventually, it was found that the sample of alumina-containing estimates consists of cryolite $\left(\mathrm{Na}_{3} \mathrm{AlF}_{6}\right)$, chiolite $\left(\mathrm{Al}_{3} \mathrm{~F}_{14} \mathrm{Na}_{5}\right)$, corundum $\left(\mathrm{Al}_{2} \mathrm{O}_{3}\right)$. quartz $\left(\mathrm{SiO}_{2}\right)$, feldspar $(\mathrm{Ca}, \mathrm{Na})(\mathrm{Al}, \mathrm{Si})$ $\left.\mathrm{AlSi}_{2} \mathrm{O}_{8}\right)$ ), carbonaceous matter and anthropogenic phase composition $(\mathrm{NaF}) \cdot 1,5 \mathrm{CaF}_{2}$. $\mathrm{AlF}_{3}$.

Moreover, two phases were detected in the samples: dark, black-gray and light, grayishwhite. It was found that these fractions have significant differences in the content of valuable components and pollutants, such as $\mathrm{SiO}_{2}, \mathrm{Fe}_{2} \mathrm{O}_{3}$.

The results of spectroscopic studies of samples of alumina-containing estimates showed significant differences in reflection coefficient, which is a favorable factor for the application of the photometric separation method.

Based on preliminary studies on the separation of alumina-containing estimates by photometric separation, the fundamental possibility of purifying contaminated material from technological impurities has been established.

\section{Sources}

1. A.E. Burdonov, E.V. Zelinskaya, IMPC 2018 - 29th International Mineral Processing Congress, 3028-3035 (2019)

2. G. Holywell, R. Breault JOM, 65(11), 1441-1451 (2013). DOI: 10.1007 / s11837-0130769-y

3. A. Solheim. E. Skybakmoen, Non-Ferrous Metals and Minerals, 300-309 (2018)

4. E.Yu. Zenkin, A.A. Gavrilenko, N.V. Nemchinova, Bulletin of the Irkutsk State Technical University, 21(3), 123-132 (2017). DOI: 10.21285 / 1814-3520-2017-3-123-132

5. V.V. Barakhtenko, A.E. Burdonov, E.V. Zelinskaya, V.V. Volyansky, A.A. Gavrilenko, Scientific foundations and practice of processing ores and industrial raw materials. 
Materials of the XXIII International scientific and technical conference held in the framework of the XVI Ural mining decade, 201-204 (2018)

6. L.I. Belykh, M.A. Maximova, Ecology and Industry of Russia, 22(9), 8-13 (2018). DOI: 10.18412 / 1816-0395-2018-9-8-13

7. V. Mann, V. Buzunov, V. Pingin, A. Zherdev, V. Grigoriev, Minerals, Metals and Materials Series, 553-563 (2019). DOI: 10.1007 / 978-3-030-05864-7_70

8. A.E. Burdonov, E.V. Zelinskaya, L.V. Gavrilenko, A.A. Gavrilenkō, Non-ferrous metals, 3, 32-38 (2018)

9. Yu.A. Romaseva, Innovation Science, 11-2, 65-67 (2016)

10. W. Wang, W. Chen, W. Gu, Metallurgist, 61(7-8), 717-725 (2017)

11. A.E. Burdonov, V.V. Barakhtenko, K.V. Prokhorov, A.A. Gavrilenko, Ore beneficiation, 4(376), 11-16 (2018) 